\title{
UNUSUAL MANIFESTATION OF ANAPLASTIC THYROID CANCER
}

\author{
Vojtěch Haas ${ }^{1}$, Petr Čelakovský1, Jindra Brtková ${ }^{2}$,Helena Hornychová ${ }^{3}$
}

Charles University in Prague, Faculty of Medicine and University Hospital Hradec Králové, Czech Republic: Department of Otolaryngology, Head and Neck Surgery ${ }^{1}$, Department of Radiology ${ }^{2}$, The Fingerland Department of Pathology ${ }^{3}$

Summary: Introduction: The authors present a rare case of a patient with symptoms consistent with retropharyngeal abscess. The diagnosis of anaplastic thyroid cancer was made after surgery and subsequent histological examination. Case report: An 80-year-old woman was referred to Dpt. of Otolaryngology, Head and Neck Surgery, Charles University Medicine Faculty, Teaching Hospital in Hradec Králové with odynophagia and pain in the left side of the neck. The patient had pronounced swelling of the left side of her neck. We could also see swelling of the posterior pharyngeal wall, more pronounced on the left side. Inflammation markers were markedly elevated. Administration of antibiotics intravenously (amoxicillin combined with clavulan acid and gentamicin) was started. A computer tomography investigation (CT) was performed and a retropharyngeal abscess was found. The existence of a tumour was considered as well. An acute endoscopic examination and a puncture of the retropharyngeal space at the site of the swelling were performed, but no pus or any other liquid was found. On the sixth day of hospitalization a second CT scan was performed. As the retropharyngeal mass was still present along with continually elevated inflammatory markers, surgical revision of the retropharyngeal space from an external approach was performed. No abscess formation was found. During the surgery, retropharyngeal lymph nodes were removed for histological examination. The histological examination of the lymph nodes identified metastasis of anaplastic thyroid cancer. Conclusions: The differential diagnosis of diseases affecting deep neck structures can be very difficult. Symptoms of inflammation dominating in the clinical picture do not exclude the possibility of malignancy. The most relevant imaging examination seems to be contrast enhanced computer tomography or magnetic resonance imaging.

Key words: Anaplastic; Thyroid cancer; Retropharyngeal abscess; Metastasis

\section{Introduction}

The most frequent clinical manifestation of anaplastic thyroid cancer is a rapidly enlarging mass at the frontal part of the neck. It is accompanied by severe compression symptoms such as dysphagia and dyspnoea with hoarseness, which could be partially due to paresis of the recurrent laryngeal nerve. We treated a patient with symptoms consistent with a retropharyngeal abscess - swelling of the posterior pharyngeal wall, odynophagia, pain in the left side of the neck, elevated inflammatory markers. The diagnosis of anaplastic thyroid cancer was unexpectedly made after surgery and a subsequent histological examination.

\section{Case report}

An 80-year-old woman was referred to Dpt. of Otolaryngology, Head and Neck Surgery, Charles University Medicine Faculty, Teaching Hospital in Hradec Králové from a local hospital where she was treated for suspected urine infection. She suffered from chronic hypertension and insulin-dependent diabetes mellitus and diabetes mellitus was not perfectly compensated. Regarding her family history, there was one relevant piece of information concerning the death of her daughter at the age of 52 from pancreatic cancer.

Odynophagia and pain in the left side of the neck appeared during the hospitalization in the local hospital accompanied with significant weight loss. Inflammation markers were significantly elevated (C-reactive protein 239 $\mathrm{mg} / \mathrm{l}$, leucocytes $\left.25 \times 10^{9} / 1\right)$. Due to the clinical findings, a computer tomography investigation (CT) was performed and a retropharyngeal abscess was found as well as hypertrophy of the left lobe of the thyroid gland. The existence of a tumour was considered as well and the patient was transferred to Dpt. of Otolaryngology, Head and Neck Surgery, Charles University Medicine Faculty, Teaching Hospital in Hradec Králové.

At the time of admission the patient had pronounced swelling of the left side of her neck. It seemed to be the left lobe of the thyroid gland with retrosternal extension. We could also see swelling of the posterior pharyngeal wall, 
more pronounced on the left side. Elevation of inflammatory markers dominated the laboratory findings (C-reactive protein $189 \mathrm{mg} / 1$, leucocytes $\left.33,5 \times 10^{9} / 1\right)$. A CT scan was repeated on the day of admission and it confirmed retropharyngeal abscess and hypertrophy of the left lobe of the thyroid gland (Figs. 1, 2, 3). An acute endoscopic exami-

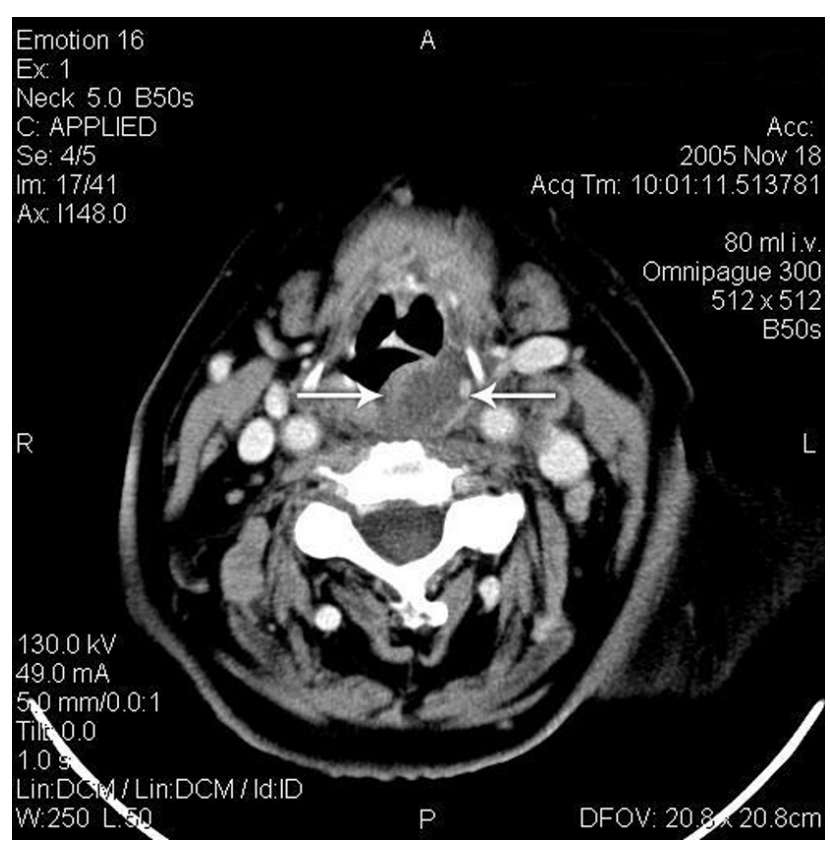

Fig. 1: CT image of a low density formation in the retropharyngeal space at the level of upper end of epiglottis.

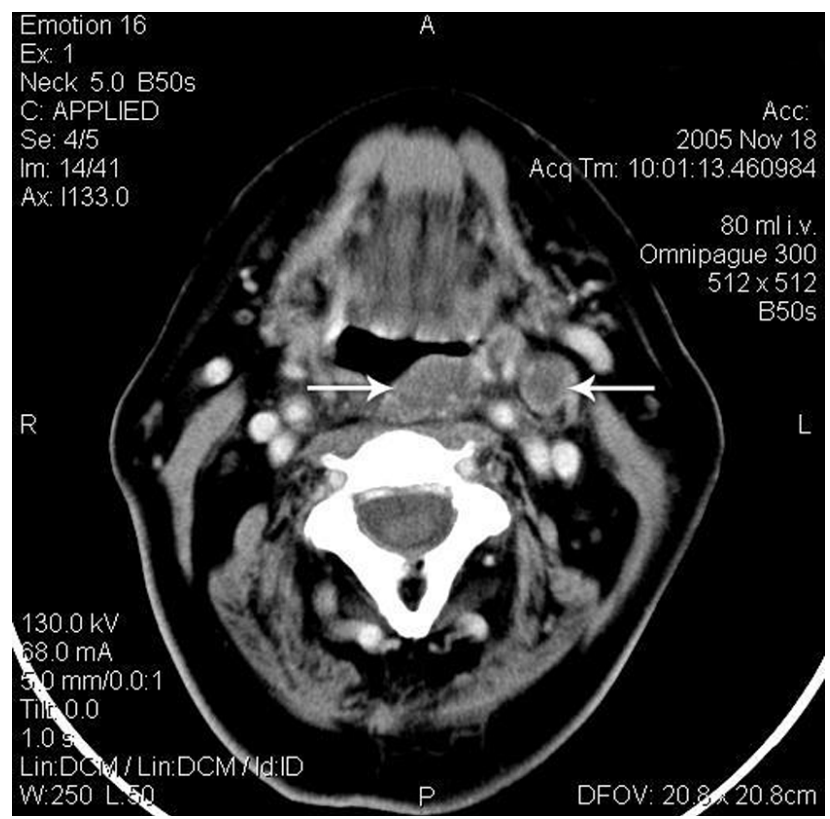

Fig. 2: CT image of a low density formation in retropharyngeal space and lymph node in reg. II with low density centre typical for colliquation at the level of radix of the tongue. nation and a puncture of the retropharyngeal space at the side of swelling were performed, but no pus or any other liquid was found. A very small amount of material taken during the retropharyngeal space punction was provided for cytological examination. Amorphous material and neutrophils were described and interpreted as signs of acute inflammation by the pathologist. Due to severe dysphagia, a nasogastric tube had to be inserted for nutrition. Administration of antibiotics intravenously (amoxicillin combined with clavulan acid and gentamicin) continued. The patient was presented to an endocrinologist and FNAC from the left lobe of the thyroid gland was taken. The pathologist described a high grade tumour of the thyroid gland or metastasis of a high grade tumour in the thyroid gland.

On the sixth day of hospitalization the second CT scan was performed. As the retropharyngeal mass was still present accompanied with continually elevated inflammatory markers and severe odynophagia, the presence of a retropharyngeal abscess was not yet excluded. Surgical revision of the retropharyngeal space from an external approach was performed. No abscess formation was found. During the surgery retropharyngeal lymph nodes were removed for histological examination. The patient's condition was stabilized during the postoperative period. She was artificially ventilated for the next 2 days then she was extubated and was able to breathe spontaneously. Blood transfusions and infusions were administered. The previous antibiotic treatment was supplemented with Metronidazol. The histological examination of the lymph nodes identified anaplastic thyroid cancer metastasis of the giant cell type with squamoid differentiation (Figs. 4, 5).

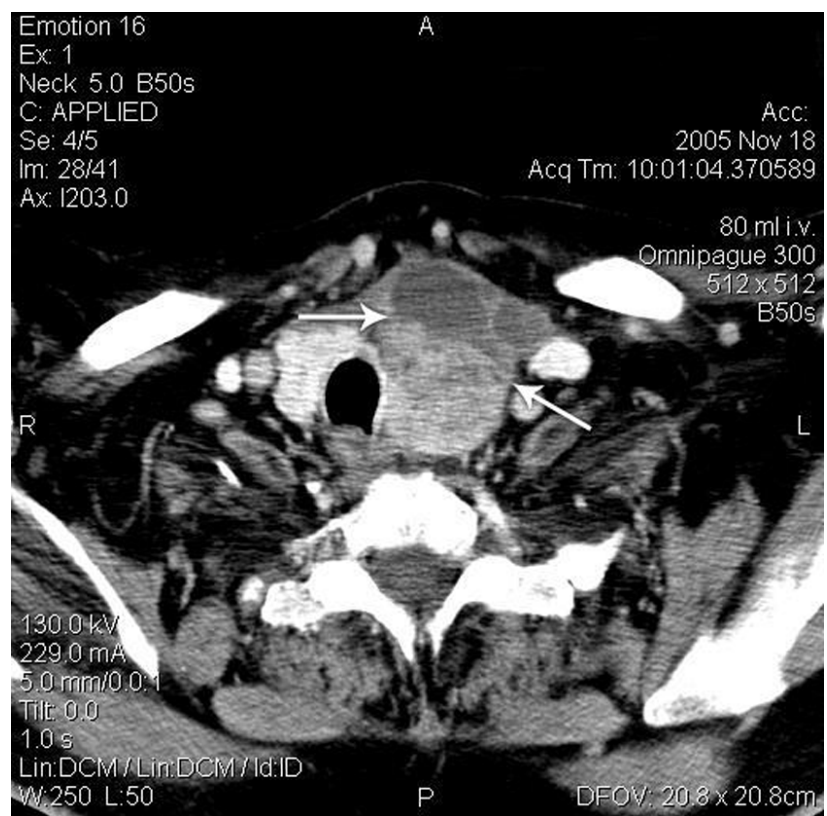

Fig. 3: CT image of tumour in the thyroid gland with colliquation. 


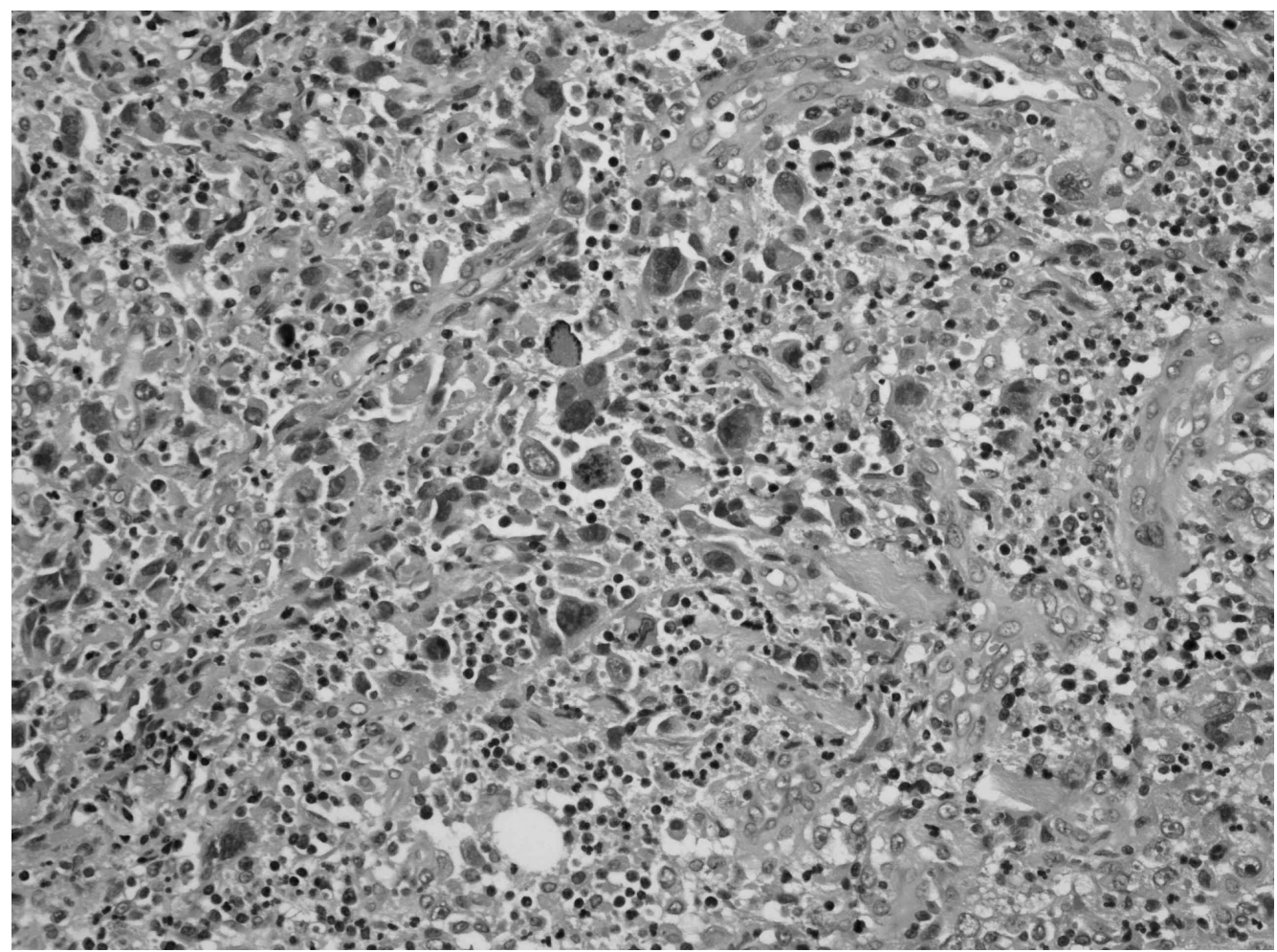

Fig. 4: Metastasis of anaplastic thyroid cancer to the lymph node, note high pleomorphism of cells and massive infiltration with neurophils (Histological examination: HE 200x).

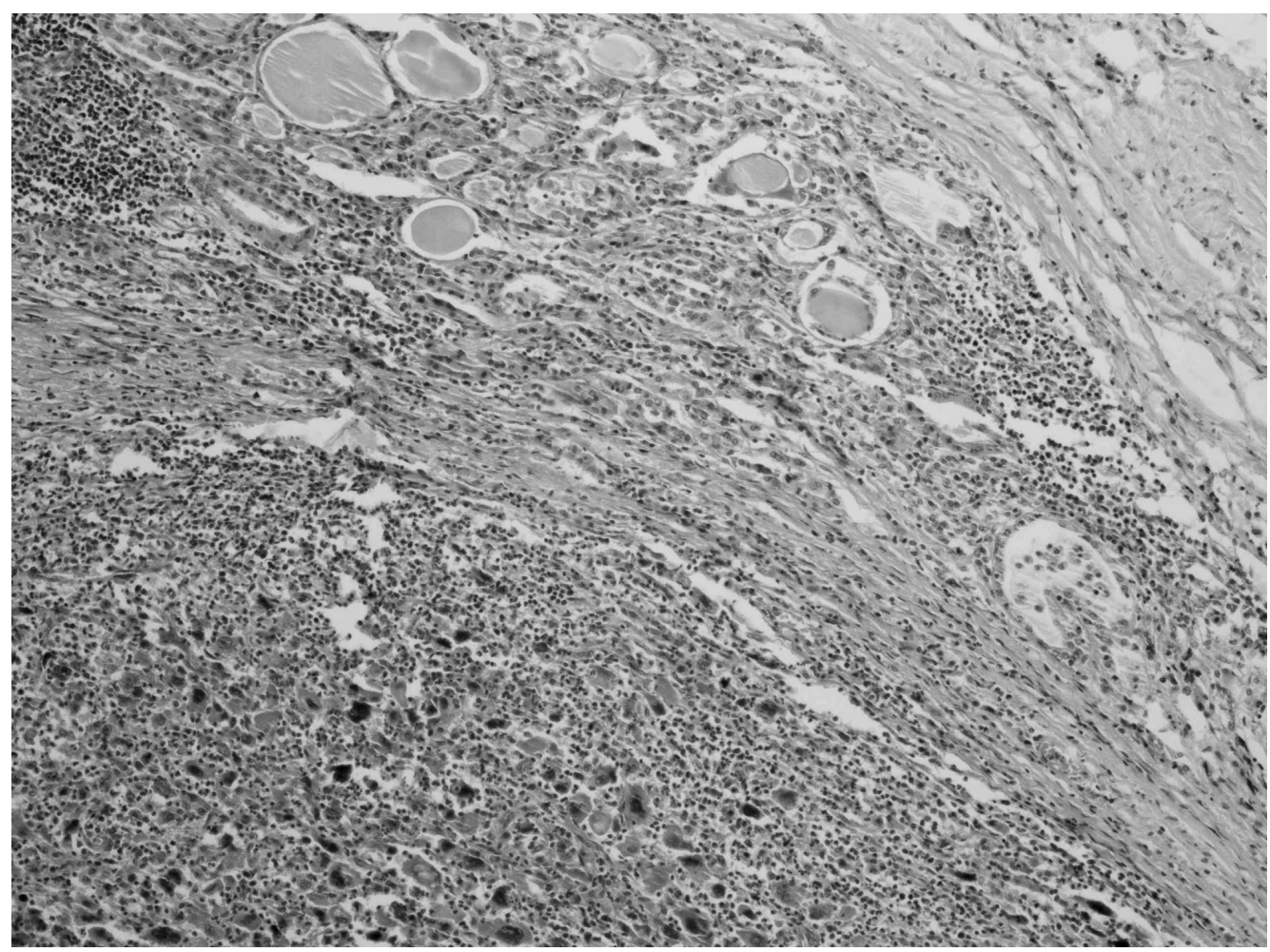

Fig. 5: Anaplastic thyroid cancer (bottom of the picture) in thyroid tissue (top of the picture) (Histological examination: HE 100x). 
On the second postoperative day the patient suddenly developed arrhythmia. Administered Digoxin had no positive effect. Diabetes mellitus was decompensated and a high dosage of insulin had to be administrated intravenously. Heart failure occurred and diuretic therapy was started. On the third postoperative day the patient lost consciousness, a comatose state progressed with apnea, and asystole followed shortly afterwards. Resuscitation was not begun due to the diagnosis of a malignant tumour with a very poor prognosis. The autopsy confirmed the diagnosis of anaplastic thyroid cancer with large necrosis and metastasis into the neck lymph nodes.

\section{Discussion}

Anaplastic thyroid cancer forms approximately 2-15\% of thyroid cancer and ranks among the most malign tumours of all $(4,5,6,7,8)$. Most often it originates from unrecognized differentiated thyroid cancer. However, it could also arise spontaneously, with no previous tumour of lower grade present $(4,5,7,8)$. The gender ratio is close to $1: 1$, although females are affected slightly more often. The patients are predominantly individuals aged $60-80$ years. It is extremely rare in a younger age groups. The tumour is very aggressive. Despite intensive treatment, patients usually die within 6-24 months after diagnosis. The most frequent clinical symptom is a rapidly enlarging mass at the frontal part of the neck usually accompanied by dyspnoea with hoarseness $(5,6)$.

Odynophagia and dysphagia were the dominant clinical symptoms in this case. A CT scan together with highly elevated inflammatory markers aroused a suspicion of inflammatory disorder. In the discussed case a suspicion of abscess formation of retropharyngeal space was conceived. After the surgery it was clear that it was a lymph node affected with metastasis of anaplastic thyroid cancer. The CT findings of the lymph node (e.g. low density centre and thin margin of high density evoked pyogenic membrane) resembled a retropharyngeal abscess. Several cases of tuberculous granuloma in thyroid gland imitating cancer have been published $(1,2,3)$. Cases of anaplastic thyroid cancer, or more precisely lymph node metastasis of thyroid cancer, re- sembling a retropharyngeal abscess, are rare. As far as we know, similar cases have not yet been described.

\section{Conclusion}

1. Differential diagnosis of diseases affecting deep neck structures can be very difficult. Symptoms of inflammation dominating the clinical picture do not automatically exclude the possibility of malignancy.

2. The most relevant imaging examination seems to be computer tomography with a bolus of contrast material or magnetic resonance imaging. Ultrasound examination could be useful only as a complementary examination.

3. Interpretation of the imaging scans is often difficult as abscess formations are hard to distinguish from necrotic tumours. A fine needle biopsy along with an ultrasound or X-ray control examination contribute to the correct diagnosis.

4. Accurate evaluation in the diagnostic process is necessary for proper treatment strategy. Surgery is not recommended for older patients in poor clinical condition who have anaplastic thyroid cancer, whereas an abscess formation in the neck is an unquestionable indication for prompt surgical intervention.

\section{Acknowledgements}

We would like to thank to Dr. Aleš Janda and Mgr. Miloslava Kettnerová for their help with the editing of the manuscript.

\section{References}

1. Allan R, O'Flynn W, Clarke SE. Tuberculosis of the thyroid bed presenting as recurrent medullary thyroid carcinoma. Tubercle 1990 Dec;71(4):301-2.

2. Al-Mulhim AA, Zakaria HM, Abdel Hadi MS, et al. Thyroid tuberculosis mimicking carcinoma: report of two cases. Surg Today 2002;32(12):1064-7.

3. Asayama I, Ishikawa T, Yamada T, Kitagawa W, Shimizu K. A case of tuberculous granuloma at the supra-sternal notch that was difficult to differentiate from a thyroid tumour. Med Sci Monit 2004; Aug;10(8):37-40.

4. Astl J. Chirurgická léčba nemocí štitné žlázy. Maxdorf, 2007:147-8.

5. Čáp J, Ryška A. Aspirační cytologie štítné žlázy. Nucleus HK, 2003:115-20.

6. Close L, Larson D, Shah J. Essentials of Head and Neck Oncology. New York: Thieme, 1998:169.

7. Dvořák J. Rakovina štítné žlázy. Praha: Nakladatelství Libri, 1997:60-3

8. Límanová Z, Němec J, Zamrazil V. Nemoci štítné žlázy. Praha: Galén, 1995: $168-70$

Submitted February 2008. Accepted December 2008.

\section{Corresponding author:}

Vojtěch Haas, MD, Department Of Otolaryngology, Head and Neck Surgery, University Hospital Hradec Králové, Sokolská 581, 50005 Hradec Králové, Czech Republic; e-mail: vojtech.haas@seznam.cz 